\title{
INOCULAÇÃO COM RHIZOBIUM E APLICAÇÃO DE NITROGÊNIO EM AMENDOIM (1)
}

\author{
ANTONIO ROBERTO GIARDINI( $\left.{ }^{2,5}\right)$, ELI SIDNEY LOPES $(2,5)$, \\ ANGELO SAVY FILHO(3,5) e ANDRÉ MARTIN LOUIS NEPTUNE( ${ }^{4}$ )
}

\begin{abstract}
RESUMO
Existe, nas nossas condições, uma população autóctone de Rhizobium capaz de nodular o amendoim (Arachis hypogaea L.), mas pouco se sabe da contribuição do nitrogênio fixado para esta planta. Foram conduzidos dois ensaios no campo, em solo de baixa fertilidade, um no período "da seca" e outro no "das águas", comparando o crescimento e a produção de plantas de amendoim inoculado com Rhizobium selecionado, com o de plantas noduladas pela população autóctone, adubadas ou não com nitrogênio. A nodulação das plantas inoculadas foi semelhante à observada nos tratamentos não inoculados, com ou sem nitrogênio. Na fase final do ciclo das plantas, houve maior acúmulo e maior taxa de absorçđ̃o diária de nitrogênio nos tratamentos inoculados ou com adubação nitrogenada, do que no controle sem inoculaça e sem nitrogênio. No ensaio da seca, năo houve aumento de produção devido à adubação nitrogenada, ou à inoculação. No ensaio das águas, houve resposta à aplicação de nitrogênio no plantio. Os resultados de produção não foram coerentes com os da marcha de absorção de $\mathbf{N}$. A produção de ensaio das águas foi equivalente a $3.400 \mathrm{~kg} / \mathrm{ha}$ para o tratamento sem nitrogênio e sem inoculaçăo.
\end{abstract}

Termos de indexação: inoculação; Rhizobium; amendoim; Arachis hypogaea L.; nitrogênio (em amendoim).

( $\left.{ }^{1}\right)$ Parte da tese de Mestrado do primeiro autor. Apresentado na 10a. Reunión Latinoamericana sobre Rhizobium (RELAR), Venezuela. Com o apoio financeiro do Convênio EMBRAPA/SAA. Recebido para publicação a 13 de setembro đe 1983.

${ }^{2}$ ) Seção de Microbiologia do Solo, Instituto Agronômico (IAC), Caixa Postal 28 - 13100, Campinas (SP).

$\left({ }^{3}\right)$ Seção de Oleaginosas, IAC.

(4) Departamento de Solos, Geologia e Fertilizantes, Escola Superior de Agricultura "Luiz de Queiroz", Universidade de São Paulo.

${ }^{5}$ ) Bolsista do CNPq. 


\section{INTRODUÇÃO}

Os trabalhos esporádicos realizados sobre a associação Rhizobium-amendoim em solós do Estado de São Paulo são insuficientes para determinar a contribuição do nitrogênio atmosférico fixado pela nodulação natural.

Por outro lado, os resultados de ensaios de adubação nitrogenada na cultura do amendoim são contraditórios com respeito à resposta da planta a esse nutriente (SICHMANN et alii, 1979).

Especula-se que a falta de resposta consistente à adubação nitrogenada no amendoim. seja devida a uma eficiente nodulação natural (CHESNEY, 1975; LOPES et alii, 1972; SICHMANN et alii, 1970; SICHMANN et alii, 1979; STURKIE \& BUCHANAN, 1973).

O objetivo deste trabalho foi comparar o desenvolvimento e a produção de plantas inoculadas com rizóbios eficientes, com o de plantas não-inoculadas, adubadas ou não com nitrogềnio aplicado em três fases do ciclo das plantas.

\section{MATERIAL E MÉTODOS}

Num latossolo roxo do Centro Experimental de Campinas, que se encontrava em pousio havia dez anos, com vegetação predominante das gramíneas capim-napier (Pennisetum purpureum) e colonião (Panicum maximum), aparecendo também beldroega (Pilea serpyllifolia), guanxuma, picão (Bidens pilosa) e algumas leguminosas dos gêneros Zornia e Indigofera, foram instalados dois experimentos com amendoim, cv. Tatu. O primeiro foi conduzido no período seco de 1979 e, o outro, com os mesmos tratamentos, nas mesmas parcelas, no período chuvoso subseqüente.

A vegetação foi roçada e retirada do local. Amostras de solo coletadas nas profundidades de $0-20$ e $20-40 \mathrm{~cm}$ revelaram os seguintes resultados de análises químicas $\left({ }^{6}\right)$ :

$\begin{array}{lccccccc}\begin{array}{l}\text { Profundidade } \\ \text { da amostra }\end{array} & \begin{array}{c}\text { M.O. } \\ \%\end{array} & \mathrm{pH} & \mathrm{Al}^{3+}\left({ }^{7}\right) & \mathrm{Ca}^{2+}\left({ }^{7}\right) \mathbf{M g}^{2+}\left({ }^{7}\right) \mathbf{K}\left({ }^{8}\right) & \left.\mathbf{P}^{8}\right) \\ & & & & & & \\ 0-20 \mathrm{~cm} \ldots & \ldots 3,3 & 5,4 & 0,2 & 0,7 & 0,4 & 28 & 1 \\ 20-40 \mathrm{~cm} \ldots 2,7 & 5,2 & 0,4 & 0,4 & 0,3 & 15 & <0,1\end{array}$

( $\left.{ }^{6}\right)$ Análise feita na Seção de Fertilidade do Solo, IAC.

(7) Dados em emg/100ml de TFSA.

( $\left.{ }^{8}\right) \mu \mathrm{g} / \mathrm{ml}$ de TFSA. 
Dois meses antes do plantio, fez-se calagem e uma adubação de recuperação e de correção em toda a área experimental. A calagem foi efetuada com calcário dolomítico, $4 \mathrm{t} / \mathrm{ha}$, conforme as recomendações vigentes (SICHMANN et alii, 1979), metade da dose antes e metade após a aração. A adubação de recuperação foi feita com superfosfato simples, $80 \mathrm{~kg}$ de $\mathrm{P}_{2} \mathrm{O}_{5} /$ hectare e cloreto de potássio, $20 \mathrm{~kg}$ de $\mathrm{K}_{2} \mathrm{O} /$ hectare, com a segunda aplicação de calcário. Na gradeação, foi aplicado sulfato de zinco comercial - $20 \mathrm{~kg} / \mathrm{ha}$ - visto que arroz cultivado em área próxima mostrou deficiência de zinco $\left({ }^{9}\right)$. A adubação de manutenção foi efetuada no plantio, empregando-se as mesmas quantidades e formas de adubos fosfatado e potássico, nos sulcos, ao lado e abaixo das sementes, nos dois ensaios.

$O$ delineamento experimental foi blocos ao acaso, com seis repetições dos seguintes tratamentos:

A - sem inoculação, sem nitrogênio;

B - sem inoculação, com nitrogênio no sulco de plantio;

C - sem inoculação, com nitrogênio em cobertura aos 25 dias;

D - sem inoculação, com nitrogênio em cobertura aos 45 dias;

E - Inoculado com a estirpe SMS-400 (= 400/Mar. Zimbabwe);

F - Inoculado com a estirpe SMS-319 (local);

G - Inoculado com a estirpe SMS-2 (local).

Nos tratamentos com nitrogênio, este nutriente foi aplicado na forma de uréia, $30 \mathrm{~kg}$ de $\mathrm{N} /$ hectare, nos dois ensaios. No segundo, as aplicações de $\mathrm{N}$, nos tratamentos $\mathrm{C}$ e $\mathrm{D}$ em cobertura, foram feitas aos 23 e aos 37 dias respectivamente.

No plantio do primeiro ensaio, as sementes não foram desinfectadas e, apesar da cuidadosa seleção das sementes, observou-se o tombamento de muitas plantas. De algumas plantas afetadas isolou-se o fungo Aspergillus niger, recentemente constatado como agente causal de tombamento nesta leguminosa (MORAES, 1979). No segundo ensaio as sementes foram desinfectadas com Thiram.

A inoculação em ambos os ensaios foi efetuada com inoculante preparado com turfa esterilizada com radiação gama, utilizando $4 \mathrm{~kg} /$ quilograma de sementes no primeiro ensaio e o dobro dessa dosagem no segundo, devido ao tratamento das sementes com fungicida. As estirpes de Rhizobium usadas nos inoculantes tiveram sua pureza comprovada; uma contagem feita pelo método da diluição e inoculação em placas, antes da instalação do experimento, revelou que tais inoculantes continham quantidade superior a $1,5 \mathrm{x}$ $10^{9}$ bactérias/grama de turfa úmida.

( $\left.{ }^{9}\right)$ SOUZA, Derly Machado de - Seção de Arroz e Cereais de Inverno, Instituto Agronômico. Informação pessoal. 
Cada parcela era composta por oito linhas de 5,0m de comprimento, espaçadas de $0,5 \mathrm{~m}$. Foram colocadas vinte sementes por metro de sulco, e feito o desbaste posterior para dez plantas.

Uma geada causou queima da parte apical das plantas do primeiro ensaio a $1 \%$ de junho de 1979 . Nessa época, as plantas estavam com vagens em formação. Doze dias depois, os ramos queimados foram podados, para exposição das folhas inferiores e melhor aproveitamento da luz solar. A partir de então, o experimento passou a ser irrigado.

Foram feitas quatro amostragens da parte aérea, para análise de nitrogênio total, e duas amostragens de raízes, para avaliação da nodulação. Em cada amostragem, foram coletadas cinco plantas. Os nódulos e a parte aérea foram lavados e secos a $60^{\circ} \mathrm{C}$. As análises de nitrogênio foram feitas pelo método indicado por BATAGLIA et alii (1978).

$O$ stand do primeiro ensaio foi prejudicado devido ao tombamento de plantas, e a produção pode ter sido afetada pela geada. Para a avaliação da produção, devido às falhas do stand, fez-se uma escolha criteriosa de quinze plantas contíguas, com bordaduras, levando em consideração a representatividade das plantas no canteiro. No segundo ano, o stand foi considerado satisfatório, e a produção de vagens avaliada em $12 \mathrm{~m}$ de linha de plantas.

\section{RESULTADOS E DISCUSSÃO}

\subsection{Nodulação}

Nos dois ensaios, as plantas não inoculadas estavam bem noduladas. No quadro 1, encontram-se os dados da nodulação do ensaio da seca. A diminuição no valor absoluto do peso ou número de nodulos observada no tratamento com adubação nitrogenada não foi significativa, embora na amostragem aos 45 dias, o número de nódulos fosse $33,6 \%$ menor que o da testemunha. $\mathrm{Na}$ segunda amostragem, as diferenças também nao foram significativas.

Os dados de nodulaçao do ensaio das águas estão no quadro 2. Neste ensaio, as plantas dos tratamentos inoculados também apresentavam nodulação semelhante à dos não inoculados. Como no ano anterior, a aplicação de nitrogênio não diminuiu o peso ou o número de nódulos nem influenciou o peso unitário dos nódulos. Entretanto, houve uma tendência em aumentar em $12 \%$ o número de nódulos no tratamento com nitrogênio no plantio, na primeira amostragem, e em $28 \%$ na segunda.

Efeito depressivo do nitrogênio combinado na nodulação tem sido observado comumente. ACUNA \& SANCHES (1969) e CHESNEY (1975) verificaram que a aplicação de nitrogênio provocou diminuição da nodulação 
do amendoim. É importante lembrar que neste ensaio o nitrogênio foi aplicado na forma de uréia, que tem menor efeito inibidor que $\mathrm{NO}_{3}^{-}$ou $\mathrm{NH}_{4}^{+}$, conforme observado por RUSCHEL et alii (1975).

Nos quadros 1 e 2, nota-se que aparentemente o nitrogênio não influenciou o peso unitário dos nódulos, como foi também observado por AYALA \& VELÁSQUEZ (1978). A média do peso unitário de nódulo do primeiro ensaio $(0,22 \mathrm{mg})$ foi cerca de $33 \%$ menor do que a do segundo ensaio $(0,33 \mathrm{mg})$. $\hat{E}$ possível que no período das águas os nódulos tenham sido maiores devido às melhores condiçōes de luminosidade, umidade e temperatura.

Nodulaçao natural abundante foi observada em amendoim anteriormente associada com ausência de resposta à inoculação (LOPES et alii, 1972), e em diversas linhagens em teste de campo (LOPES et alii, 1976).

QUADRO 1 - Peso e número de nódulos/planta, e peso de um nódulo, observados em amendoim em duas épocas de amostragem, no experimento da seca. Média de seis repetiçбes

\begin{tabular}{|c|c|c|c|c|c|c|}
\hline \multirow{3}{*}{ TRATAMENTO } & \multicolumn{3}{|c|}{ NODULAÇÃO AOS 45 DIAS } & \multicolumn{3}{|c|}{ NODULAÇĀO AOS 84 DIAS } \\
\hline & \multicolumn{2}{|c|}{ Nódulos/Planta } & $\begin{array}{l}\text { Peso de } \\
\text { um } \\
\text { nódulo }\end{array}$ & \multicolumn{2}{|c|}{ Nódulos/Planta } & \multirow{2}{*}{$\begin{array}{c}\begin{array}{c}\text { Peso de } \\
\text { um } \\
\text { nódulo }\end{array} \\
\mathrm{mg}\end{array}$} \\
\hline & $\mathrm{mg}$ & no & $\mathrm{mg}$ & $\mathrm{mg}$ & no & \\
\hline \multicolumn{7}{|l|}{ Sem inoculação } \\
\hline Sem nitrogênio & 33,0 & 138 & 0,24 & 96,6 & 373 & 0,26 \\
\hline Com $\mathbf{N}$ no plantio & 20,0 & 103 & 0,19 & 75,1 & 326 & 0,23 \\
\hline Com $\mathrm{N}$ aos 24 dias & 25,2 & 124 & 0,20 & 81,6 & 372 & 0,22 \\
\hline Com $\mathrm{N}$ aos 45 dias & - & - & - & 79,5 & 331 & 0,24 \\
\hline \multicolumn{7}{|l|}{ Inoculação com } \\
\hline SMS-400 & 33,1 & 145 & 0,23 & 94,8 & 432 & 0,22 \\
\hline SMS-319 & 37,2 & 160 & 0,23 & 94,0 & 389 & 0,24 \\
\hline SMS-2 & 35,0 & 142 & 0,25 & 76,4 & 347 & 0,22 \\
\hline C.V. \% & 36 & 17 & - & 27 & 13 & - \\
\hline \multirow[t]{2}{*}{$\mathrm{F}$} & ns & ns & - & ns & ns & - \\
\hline & & & $\bar{x}=0,22$ & & - & $\overline{\mathbf{x}}=0,23$ \\
\hline
\end{tabular}

Os traços referem-se a dados não coletados, ou não calculados 
QUADRO 2 - Peso e número de nódulos/planta, e peso de um nódulo, observados em amendoim em duas épocas de amostragem, no experimento das águas. Média de seis repetições

\begin{tabular}{|c|c|c|c|c|c|c|}
\hline \multirow{3}{*}{ TRATAMENTO } & \multicolumn{3}{|c|}{ NODULAÇÃO AOS 37 DIAS } & \multicolumn{3}{|c|}{ NODULAÇÃO AOS 78 DIAS } \\
\hline & \multicolumn{2}{|c|}{ Nódulos/Planta } & \multirow{2}{*}{$\begin{array}{c}\begin{array}{c}\text { Peso de } \\
\text { um } \\
\text { nódulo }\end{array} \\
\text { mg }\end{array}$} & \multicolumn{2}{|c|}{ Nódulos/Planta } & \multirow{2}{*}{$\begin{array}{c}\begin{array}{c}\text { Peso de } \\
\text { um } \\
\text { nódulo }\end{array} \\
\mathrm{mg}\end{array}$} \\
\hline & $\mathrm{mg}$ & no & & $\mathrm{mg}$ & no & \\
\hline \multicolumn{7}{|l|}{ Sem inoculaçāo } \\
\hline Sem nitrogênio & 29,9 & 117 & 0,25 & 95,6 & 192 & 0,49 \\
\hline Com $N$ no plantio & 26,6 & 131 & 0,20 & 92,8 & 246 & 0,37 \\
\hline Com $\mathrm{N}$ aos 23 dias & 26,2 & 116 & 0,22 & 88,9 & 228 & 0,38 \\
\hline Com $N$ aos 37 dias & 28,5 & 106 & 0,27 & 120,0 & 272 & 0,44 \\
\hline \multicolumn{7}{|l|}{ Inoculado com } \\
\hline SMS-400 & 30,0 & 115 & 0,26 & 85,4 & 235 & 0,36 \\
\hline SMS-319 & 39,8 & 148 & 0,26 & 123,5 & 322 & 0,38 \\
\hline SMS-2 & 35,8 & 107 & 0,33 & 112,5 & 230 & 0,48 \\
\hline C.V. \% & 28 & 28 & - & 30 & 28 & - \\
\hline \multirow[t]{2}{*}{$\mathbf{F}$} & ns & ns & - & ns & ns & - \\
\hline & & & $\overline{\mathbf{x}}=0,26$ & & & $\overline{\mathbf{x}}=0,41$ \\
\hline
\end{tabular}

Os traços referem-se a dados não coletados, ou não calculados

\subsection{Acúmulo de nitrogênio}

Nas figuras 1 e 2 estão as curvas de acúmulo de nitrogênio e os histogramas das taxas médias de assimilação diária de nitrogênio respectivamente do primeiro e segundo ensaios.

Pode-se verificar que ate 57-59 dias, as plantas dos tratamentos com adição de nitrogênio (Figuras 1A e 2A) e com inoculação (Figuras 1B e 2B) apresentaram curvas de absorção de nitrogênio semelhantes às das plantas dos tratamentos não inoculados. Nos dois ensaios, para o último período de amostragem, menor acúmulo de nitrogênio foi detectado no tratamento não inoculado nos dois ensaios. Na época da seca, o adubo nitrogenado aplicado no plantio não promoveu aumentos em relação ao controle, na quantidade de nitrogênio absorvida até 84 dias (Figura 1A). O aplicado aos 45 dias foi mais bem aproveitado que o aplicado aos 25 dias. Para a época das águas, o 

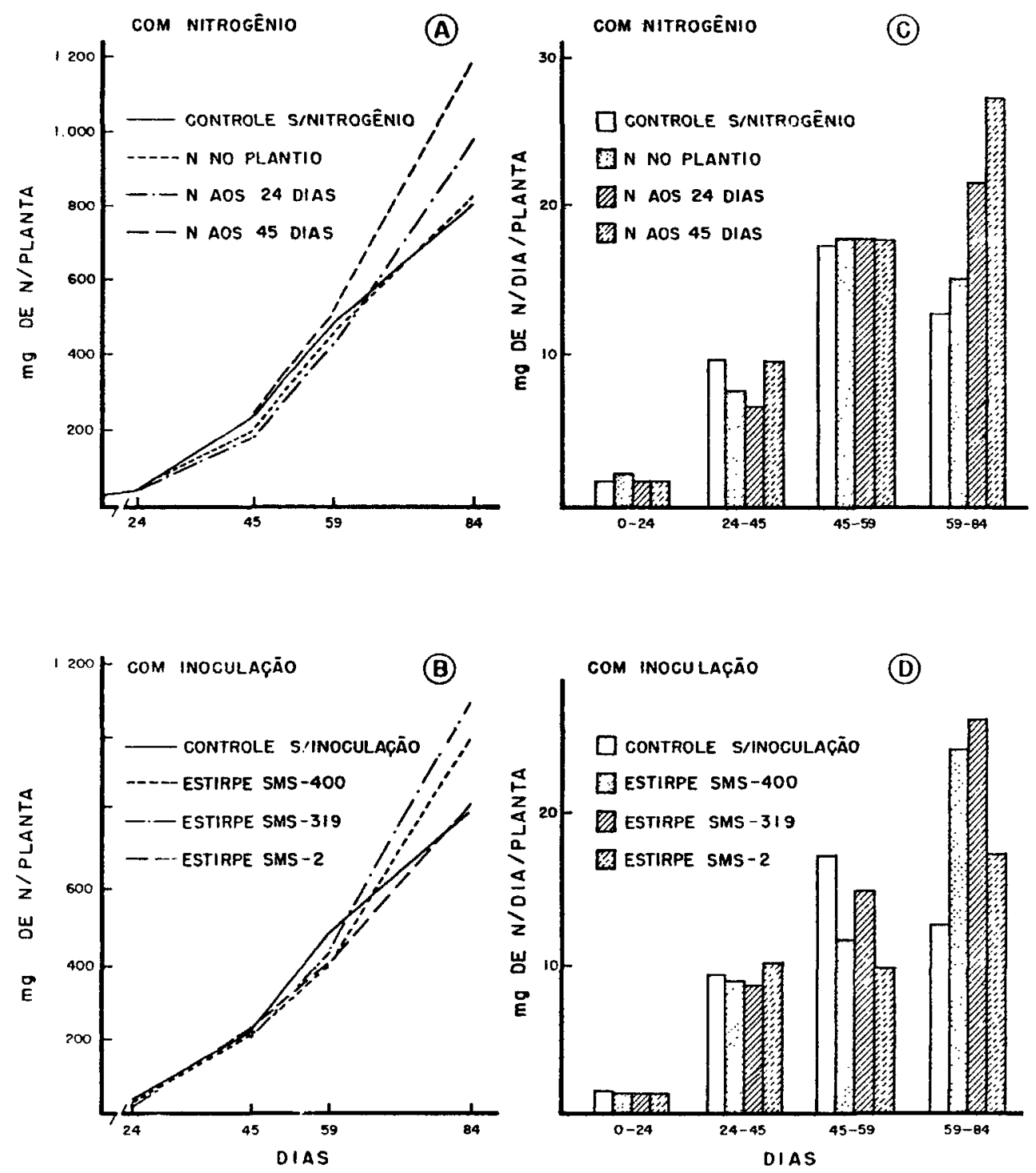

FIGURA 1 - Marcha e taxa de absorção diária de nitrogênio observadas em amendoim, durante 84 dias, num ensaio de campo sobre inoculação e adubação nitrogenada. Marcha de absorção: A: com nitrogênio; B: com inoculação. Taxa de absorção diária: C: com nitrogênio; $\mathrm{D}$ : com inoculação. 
adubo aplicado foi igualmente aproveitado, independente da época (Figura 2A). Convém lembrar que o processo de translocação de nitrogênio para as vagens já se iniciara nessa ocasião, e que a taxa de translocação poderia ser diferente para a época da seca e das águas para os diferentes tratamentos de adubação nitrogenada. COELHO \& TELLA (1967a, 1967b) verificaram, em ensaio em vaso, que o amendoim assimila maior quantidade de nitrogênio combinado na fase de formação de vagem. Maiores valores de acúmulo de nitrogênio foram também encontrados no período final, em ambos os ensaios, particularmente nos tratamentos de inoculação com as estirpes SMS-319 e SMS-400 (Figuras 1B e 2B). WYNNE et alii (1978) e RATNER et alii (1979) verificaram que a atividade da nitrogenase no amendoim é máxima no final do ciclo da cultura.

Nos ensaios da seca e das águas, para os três primeiros períodos amostrados, não se observaram diferenças significativas (Figuras 1C, 1D, $2 \mathrm{C} \mathrm{e}$ 2D) na taxa de absorção de nitrogênio (média do nitrogênio absorvido por dia, por planta). Para a amostragem do período entre 45 e 59 dias, houve uma tendência de menores valores de absorção diária de nitrogênio nos tratamentos inoculados para as três estirpes. Na última amostragem, entretanto, os valores absolutos da taxa de absorção de nitrogênio dos tratamentos com inoculação, ou com adubo nitrogenado, são bem maiores que as do controle.

Dadas as diferenças nas taxas de assimilação de nitrogênio entre os tratamentos inoculados e não-inoculados, constatadas no último período de amostragem, é válido supor que a maior parte dos nódulos formados nos tratamentos inoculados fossem induzidos pelas estirpes dos inoculantes. $\mathrm{O}$ tratamento de inoculação com a estirpe SMS-2 apresentou taxa de assimilação de nitrogênio estatisticamente semelhan te ao tratamen to sem inoculação, nos dois ensaios. É interessante observar que análises de ureídeos realizadas nas folhas amostradas aos 84 dias, no segundo ensaio, revelaram maiores teores nas amostras dos tratamentos sem adubação nitrogenada, indicando que o processo biologico de fixação parece ter sido diminuído devido à adição de nitrogênio (TEIXEIRA et alii, 1981).

\subsection{Produção}

No quadro 3 estão as produçðes de vagens dos dois ensaios: no primeiro, os dados referem-se à produção por 15 plantas e, no segundo, por $12 \mathrm{~m}$ de linha.

No primeiro ensaio, as diferenças entre as médias de produção dos diversos tratamentos nao foram significativas, apesar de que os tratamentos com a estirpe SMS-2 e com $\mathrm{N}$ aos 45 dias produziram 15 e $20 \%$, respectivamente, mais que o valor do controle. Considerando as diferenças nos acúmulos de nitrogênio já comentadas, as ausências de resposta à adubação nitrogena- 


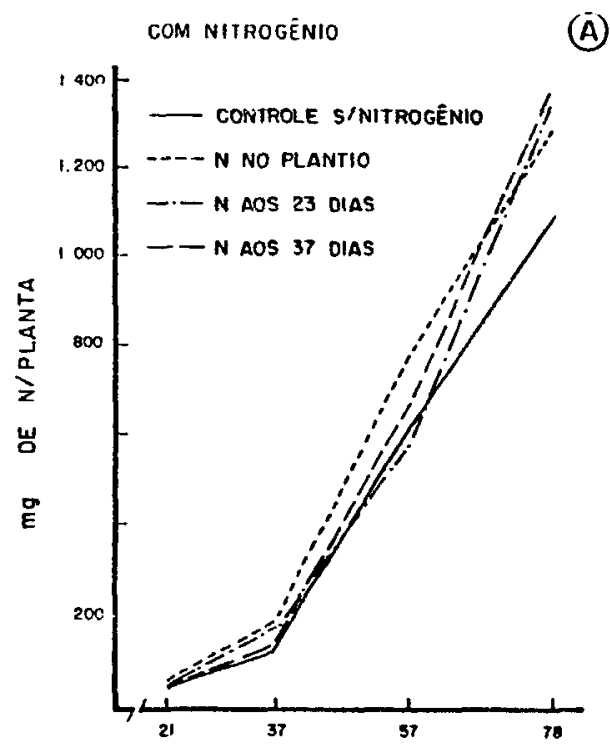

(A)

COM NITROGẼNiO

(C)
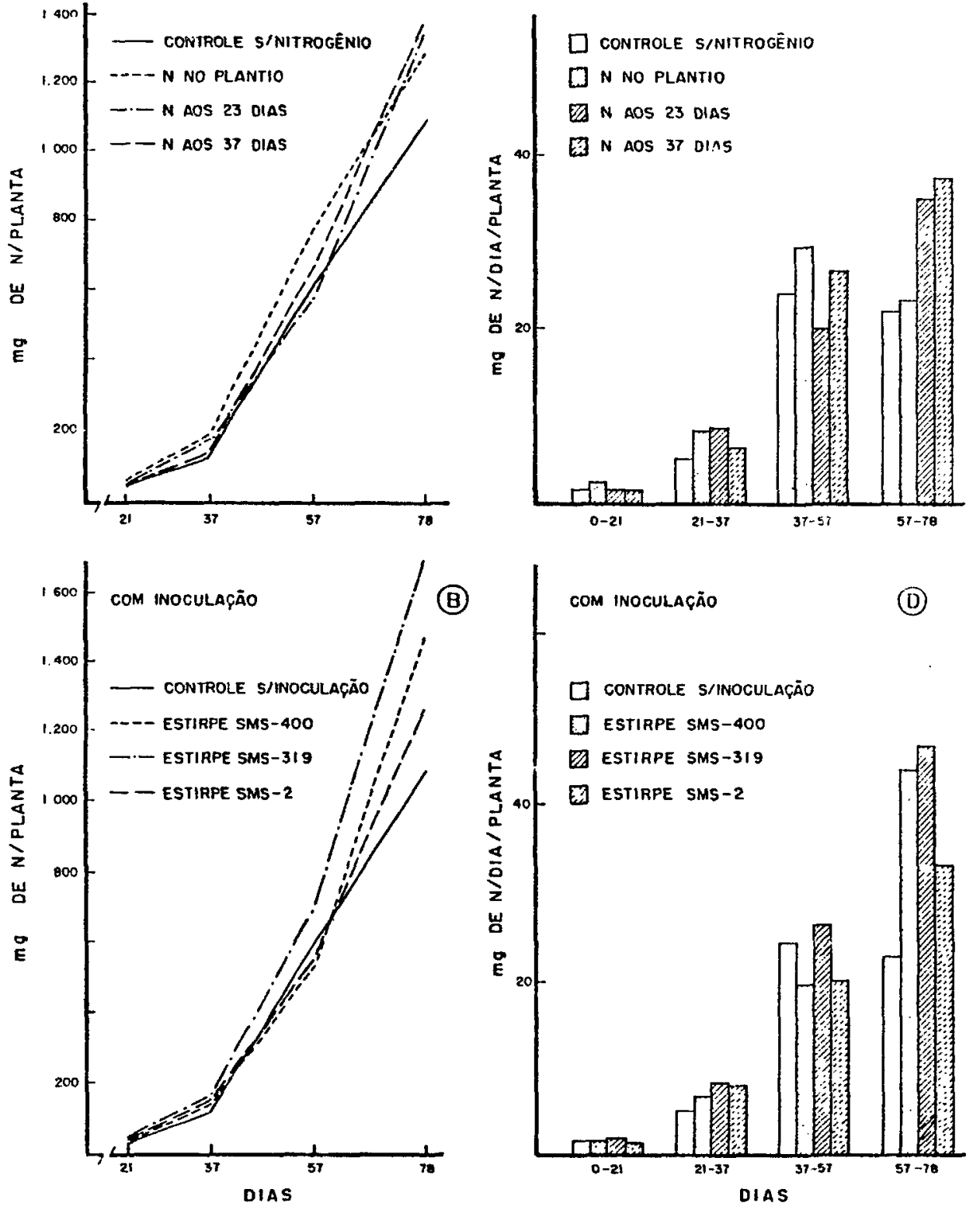

FIGURA 2 - Marcha e taxa de absorção diária de nitrogênio observadas em amendoim, durante 78 dias, num ensaio de campo sobre inoculação e adubação nitrogenada. Marcha de absorção: A: com nitrogênio; B: com inoculação. Taxa de absorção diária: C: com nitrogênio; D: com inoculação. 
da e à inoculação, na produção, podem ser atribuídas ao efeito prejudicial da geada, mais acentuado nos tratamentos com plantas mais desenvolvidas, ou por outro fator limitante não controlado.

QUADRO 3 - Produções médias de amendoim, observadas em dois ensaios com inoculação e adubação nitrogenada, conduzido na seca e nas águas: no primeiro, os dados referem-se à produção por 15 plantas, e, no segundo, à produção por $12 \mathrm{~m}$ de linha, e a porcentagem em relação à testemunha (sem inoculação e sem nitrogênio). Médias de seis repetições

\begin{tabular}{|c|c|c|c|c|}
\hline \multirow{2}{*}{ TRATAMENTO $\left({ }^{1}\right)$} & \multicolumn{2}{|c|}{19 Ensaio (seca) } & \multicolumn{2}{|c|}{20 Ensaio (águas) } \\
\hline & $\begin{array}{l}\text { Produção/15 } \\
\text { plantas }\end{array}$ & $\begin{array}{l}\text { Produção } \\
\text { relativa }\end{array}$ & $\begin{array}{l}\text { Produção/12m } \\
\text { de linha }\left({ }^{2}\right)\end{array}$ & $\begin{array}{l}\text { Produção } \\
\text { relativa }\end{array}$ \\
\hline & $\mathrm{g}$ & $\%$ & $\mathrm{~kg}$ & $\%$ \\
\hline \multicolumn{5}{|l|}{ Sem inoculação } \\
\hline Sem nitrogênio & 192,0 & 100 & $2,06 \mathrm{~b}$ & 100 \\
\hline Com $\mathrm{N}$ no plantio & 196,0 & 102 & $2,45 \mathrm{a}$ & 120 \\
\hline Com $\mathrm{N}$ aos 24 dias & 204,0 & 106 & $2,16 a b$ & 105 \\
\hline Com $N$ aos 45 dias & 231,0 & 120 & 2,17 & 105 \\
\hline \multicolumn{5}{|l|}{ Inoculado com } \\
\hline SMS-400 & 187,0 & 107 & $2,27 \mathrm{ab}$ & 110 \\
\hline SMS-319 & 204,0 & 106 & $2,32 \mathrm{ab}$ & 113 \\
\hline SMS-2 & 221,0 & 115 & $2,09 \mathrm{~b}$ & 101 \\
\hline C.V. & $17 \%$ & & $12 \%$ & \\
\hline
\end{tabular}

( $\left.{ }^{1}\right)$ No segundo ensaio as aplicações de $\mathrm{N}$ foram aos 23 e 37 dias do plantio.

$\left({ }^{2}\right)$ Médias com letras em comum não diferem (Duncan, $5 \%$ ).

A produção média do experimento das águas (segundo ensaio) foi $85 \%$ maior que a produção média atual do Estado de São Paulo $(2.000 \mathrm{~kg} / \mathrm{ha})$, e ainda assim menor que produções relatadas por outros autores (RATNER et alii, 1979; SICHMANN et alii, 1979). Neste ensaio, houve resposta à aplicação de nitrogênio no plantio, contribuindo para um aumento de $20 \%$ na produção.

O nitrogênio fixado biologicamente, mais o absorvido do solo, foi suficiente, portanto, para uma produção de $4.000 \mathrm{~kg} /$ ha de vagens. Não é possível diferenciar, por estes resultados, a contribuição do nitrogênio do 
solo e da fixação, nem se as estirpes que possibilitaram os altos níveis de produção, sem adubação nitrogenada, poderiam suprir nitrogênio necessário para níveis de produção ainda mais elevados, como observados em Israel (RATNER et alii, 1979).

E possível que o molibdênio tenha limitado a fixação do nitrogênio, pois, na mesma área, foram obtidas produções equivalentes a $4.700 \mathrm{~kg}$ de vagens de amendoim por hectare, em parcelas inoculadas, sem nitrogênio, com resposta à aplicação de molibdênio $\left({ }^{10}\right)$.

\section{SUMMARY}

\section{COMPARISON AMONG RHIZOBIUM STRAINS INOCULATIONS AND NITROGEN APPLICATIONS ON PEANUT, IN FIELD CONDITIONS}

Two field experiments were carried out with peanut in the same area on a limed and fertilized "cerrado soil" (originally acidic and low fertility). The first experiment was carried out in the autumn/winter (dry season), and the second one in the subsequent spring/summer (wet season), in Campinas, State of São Paulo, Brazil. Plant development and production of inoculated (three Rhizobium strains) and nitrogen fertilized treatments (at planting 25 and 45 days after planting) were compared with non-inoculated and non- $\mathrm{N}$-fertilized control. Nodulation of inoculated plants was similar to those of non-inoculated, with or without nitrogen. Greater accumulations, and rates for average daily uptake of nitrogen were observed for inoculated as well as for nitrogen fertilized plants, as compared to the control. In the autumn/ winter experiment there was no increase in pod production neither due to nitrogen or to inoculation. In the spring/summer experiment however, the pod production was higher with nitrogen $(30 \mathrm{~kg} / \mathrm{N} / \mathrm{ha})$ at planting, although higher nitrogen accumulations in plant shoots (sampled 84 days after planting) were observed treatments with two of the three inoculated strains.

Index terms: inoculation; Rhizobium; peanut; Arachis hypogaea L. nitrogen.

\section{REFERENCIAS BIBLIOGRAFICAS}

ACUNA, J. \& SANCHES, P.C. Resposta do amendoim a aplicação do nitrogênio, fósforo e potássio, no solo franco-arenoso de savana no Estado de Monaga. Fertilité; 35:3-9, 1969.

AYALA, B.L.B. \& VELÁSQUEZ, L. Evaluacion agronômica de once (11) cepas de Rhizobium sp inoculadas em mani Arachis hypogaea L., cultivados en suelos de los llanos orientales de Venezuela. In: REUNION LATINOAMERICANA SOBRE RHIZOBIUM, 9., Mexico, 1978.

p.31-44.

$\left({ }^{10}\right)$ Dechen, A.R. \& Quaggio, J.A. Comunicação pessoal. 
BATAGLIA, O.C.; TEIXEIRA, J.P.F.; FURLANI, A.M.C. \& GALLO, J.L. Análise química de plantas. Campinas, Instituto Agronômico, 1978. 31p. (Circular, 87)

CHESNEY, H.A.D. Fertilizer studies with groundnuts on the Brown sands of Guyana. Agronomy Journal, 67:7-10, 1975.

COELHO, F.A.S. \& TELLA, R. Absorção de nutrientes por plantas de amendoim na cultura de outono. Bragantia, Campinas, 26:235-252, 1967a. $\&$ Absorção de nutrientes pela planta de amendoim em cultura de primavera. Bragantia, Campinas, 26:393-408, $1967 \mathrm{~b}$.

LOPES, E.S.; TELLA, R.; ROCHA. J.L.V. \& IGUE, T. Inoculação de sementes de amendoim (Arachis hypogaea L.). Bragantia, Campinas, 31:XXVII-XXXIV, 1972. (Nota, 6)

; SAVY Fo, A.; OLIVEIRA, M.L.C.; GIARDINI, A.R. \& POMPEU, A.S. Observação da nodulação natural em cultivares de amendoim (Arachis hypogaea L.). Bragantia, Campinas, 35: XI-XII, 1976. (Nota, 3)

MORAES, S.A. Ocorrência da podridão do colo em amendoim (Arachis hypogaea L.) causada por Aspergillum niger van Tiegh, no Estado de São Paulo. Ecossistema, Pinhal, 4:123-126, 1979.

RATNER, E.I.; LOBEL, R.; FELDHAY, H. \& HARTZOOK, A. Some characteristics of symbiotic nitrogen fixation, yield, protein and oil acumulation in irrigated peanuts (Arachis hypogaea L.). Plant and Soil, The Hague, 51:373-386, 1979.

RUSCHEL, A.P.; SUHET, A.R.; VIANNI, R.; \& ALMEIDA, D.L. Efeito de diferentes fontes de nitrogênio e da inoculação na produção de sementes, proteína e óleo em dois cultivares de soja. Pesquisa Agropecuária Brasileira, Brasília, Sér. Agron. 10:19-23, 1975.

SICHMANN, W. NEPTUNE, A.M.L. \& SABINO, N. Acumulação de macronutrientes pelo amendoim (Arachis hypogaea L.) cultivado em outono, na época da seca. Anais da Escola Superior de Agricultura "Luiz de Queiroz", Piracicaba, 27:393-409, 1970.

, SAVY Fo, A. \& LASCA, D.H.C. Adubação do amendoim. Campinas, Coordenadoria de Assistência Técnica Integral, 1979. 39p. (Boletim Técnico, 136)

STURKIE, D.G. \& BUCHANAN, G.A. In: Peanuts culture and uses. Roanoke, Virginia, Stone Printing Co. 1973. 299p.

TEIXEIRA, J.P.F.; SILVA, M.T.R.; LOPES, E.S. \& GIARDINI, A.R. Ocorrência de ureídeos em folhas de amendoim como indicativo da fixação simbiótica de nitrogênio atmosférico. Bragantia, Campinas, 40:193-197, 1981. 
WYNNE, J.C.; ELKAN, G.H.; SCHNEEWEIS, T.J.; ISLEIB, T.B.; PRESTON, C.M. \& MEISNER, C.A. Increasing nitrogen fixation of the peanut. American Peanut Research and Education Association Proceedings, 10:22-29, 1978. 